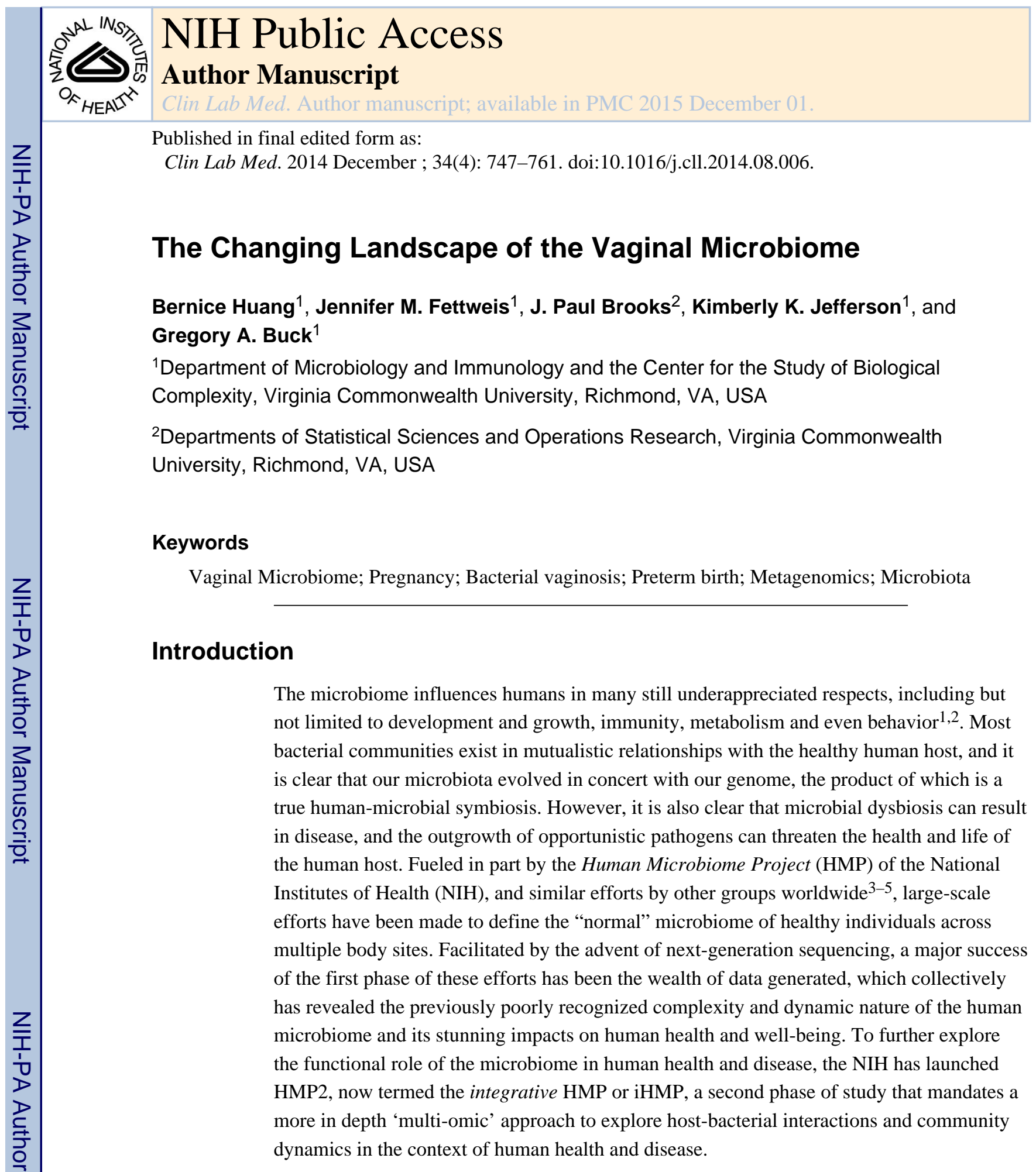

The microbiome influences humans in many still underappreciated respects, including but not limited to development and growth, immunity, metabolism and even behavior ${ }^{1,2}$. Most bacterial communities exist in mutualistic relationships with the healthy human host, and it is clear that our microbiota evolved in concert with our genome, the product of which is a true human-microbial symbiosis. However, it is also clear that microbial dysbiosis can result in disease, and the outgrowth of opportunistic pathogens can threaten the health and life of the human host. Fueled in part by the Human Microbiome Project (HMP) of the National Institutes of Health (NIH), and similar efforts by other groups worldwide ${ }^{3-5}$, large-scale efforts have been made to define the "normal" microbiome of healthy individuals across multiple body sites. Facilitated by the advent of next-generation sequencing, a major success of the first phase of these efforts has been the wealth of data generated, which collectively has revealed the previously poorly recognized complexity and dynamic nature of the human microbiome and its stunning impacts on human health and well-being. To further explore the functional role of the microbiome in human health and disease, the NIH has launched mere now termed the integrative HMP or iHMP, a second phase of study that mandas a dynamics in the context of human health and disease.

(C) 2014 Elsevier Inc. All rights reserved.

*Corresponding author: Gregory A. Buck, 1101 E. Marshall Street, PO Box 980678 Richmond, VA 23298, gabuck@ vcu.edu, Office: 804-827-0026, Fax: 804-828-1961.

The authors have nothing to disclose

Publisher's Disclaimer: This is a PDF file of an unedited manuscript that has been accepted for publication. As a service to our customers we are providing this early version of the manuscript. The manuscript will undergo copyediting, typesetting, and review of the resulting proof before it is published in its final citable form. Please note that during the production process errors may be discovered which could affect the content, and all legal disclaimers that apply to the journal pertain. 
The Vaginal Microbiome Consortium (vmc.vcu.edu) at Virginia Commonwealth University (VCU) has a two-stage project funded by the NIH HMP1 and iHMP programs. The first stage, the Vaginal Human Microbiome Project, is a cross-sectional community based study on over 6,000 visitors to multiple women's clinics in Central Virginia, with the goal of investigating the roles of the vaginal microbiome in women's urogenital health. Vaginal and buccal samples were collected from women volunteers over the age of 18 , with the exception of women who were incarcerated, independent of their state of health. Embedded within this study is the collection and analysis of samples from approximately 250 monozygotic and dizygotic twin pairs from VCU's Mid Atlantic Twin Registry ${ }^{6}$. The microbial populations in each sample were defined by high-throughput metagenomic 16S rRNA gene sequencing, whole metagenome shotgun analysis, and by microbiologically culturing, cloning by single colony isolation and sequencing of the genomes of target bacterial species or taxa. In the Multi-Omic Microbiome Study-Pregnancy Initiative, the second stage of this program, samples from over 2,000 pregnant women and their infants are being collected longitudinally at multiple prenatal visits during their pregnancies, at delivery and at early post natal visits. Samples are collected from the vagina, rectum, nares, mouth and skin from each participant over the age of 15 who is not incarcerated and who is not a surrogate.

Samples from these participants are subjected to six 'omics' technologies: $i$ ) targeted 16S rRNA gene surveys to generate species-level microbiome profiles; ii) whole genome sequencing of relevant taxa that we are able to culture and bacteriologically clone; iii) whole metagenomic shotgun sequencing (WMGS) to generate 'gene-centric' and 'taxonomycentric' profiles of the metabolic and pathogenic potential, and to generate genome sequences of abundant taxa that we are unable to cultivate; $i v$ ) metatranscriptomic analysis to assess expression levels of relevant prokaryotic and host genes; $v$ ) metabolomic/lipidomic analyses to provide insight into the signaling and regulatory pathways controlling the environment in the vagina; and vi) immunoproteomic analyses to measure cytokines and immune factors impacting vaginal function during pregnancy. The objective of the latter study is to elucidate the role(s) of the vaginal microbiome in the etiology or prevention of adverse outcomes of pregnancy, with a specific focus on preterm birth and stillbirth.

\section{The vaginal microbiome}

Microbial communities play fundamental roles in promoting homeostasis in the vagina and in preventing colonization of pathogenic bacteria, but the mechanisms by which they exert their influence are not well defined. Historically, studies of vaginal microbiota applied conventional culture-dependent microbiological strategies, which, because most of the microbial species in these environments are intractable to standard cultivation technologies, produce only a partial picture of the overall microbiome. Development of cultureindependent approaches based on analysis of 16S rRNA gene sequences, coupled with the establishment of high-throughput so-called 'next-generation' sequencing technology ${ }^{7}$, now permits deep, high-resolution, species-level classification ${ }^{8}$ of vaginally-relevant bacteria and is dramatically broadening our understanding of the vaginal ecosystem and the complex interactions between host and microbial factors within it. 
Since their first description in 1892 by Gustav Doderlein, lactobacilli have been considered the dominant inhabitants of vaginal communities and the cornerstone of vaginal health ${ }^{9}$. The prevailing hypothesis holds that vaginal Lactobacillus species promote a protective environment in the vagina by lowering the $\mathrm{pH}$ through lactic acid production and by competing for nutrients and space. Lactobacillus species also produce other metabolites, bacteriocins and hydrogen peroxide $\left(\mathrm{H}_{2} \mathrm{O}_{2}\right)$, which may contribute to the inhibition of growth of other microorganisms ${ }^{10,11}$, and therefore have the potential to actively protect the vaginal ecosystem from adverse microbiota.

Recent studies have produced major advances in our understanding of the composition of vaginal microbial communities. Collectively, this research has revealed the presence of several distinct types of communities that differ in both the composition and relative abundance of species or taxa. The prevalence of these communities varies significantly among different racial and ethnic groups ${ }^{12-14}$. This observation is important because differences in microbial composition may radically influence how vaginal communities respond to infections or other imbalances. Here, we review studies of the vaginal microbiome, including factors that influence its composition and its role in the maintenance of vaginal health.

\section{Healthy Lactobacillus dominated vaginal flora}

The genus Lactobacillus is comprised of over 130 lactic acid producing species that inhabit diverse environments; over 20 of which have been detected in the vagina ${ }^{15,16}$. Unlike most other body sites, healthy vaginal communities have been considered to be those dominated by only one or two species, the most common of which are Lactobacillus iners, Lactobacillus crispatus, Lactobacillus jensenii and Lactobacillus gasseri ${ }^{12,17}$. Lactobacilli use several mechanisms to inhibit colonization by other bacteria including pathogens. Vaginal epithelial cells produce glycogen, which lactobacilli ferment, producing D- and Llactic acid ${ }^{18}$. Some species produce hydrogen peroxide in vitro; however, recent studies suggest that in the hypoxic conditions that exist in the vagina, concentrations may never achieve levels that are inhibitory to other bacteria ${ }^{19}$. In vaginal fluid, bacteria associated with bacterial vaginosis can be suppressed with lactic acid but not hydrogen peroxide 20,21 . Some species also produce bacteriocins that can directly kill other bacterial species ${ }^{22}$. Lactobacilli also likely outcompete other organisms for nutrients or receptors at the epithelial cell surface ${ }^{23-25}$. These inhibitory mechanisms differ among Lactobacillus species. Comparative genomic analyses of $L$. crispatus, L. gasseri, L. iners and L. jensenii have provided evidence that each Lactobacillus species possesses a unique repertoire of protein families and suggest these differences may reflect specific community adaptations ${ }^{26,27}$. Future studies aimed at characterizing the functional roles of these speciesspecific protein families and genes may provide important insight into how these common vaginal bacteria impact women's health.

Lactobacilli can also inhibit pathogen colonization by competing for host cell receptors used by urogenital pathogens such as Gardnerella vaginalis, Neisseria gonorrhoeae, Candida albicans, Staphylococcus aureus, group B Streptococcus species (GBS), Pseudomonas aeruginosa, Streptococcus agalactiae, Escherichia coli and Prevotella bivia ${ }^{23,28-30}$. Thus, 
lactobacilli with a higher affinity for host cell receptors can displace adherent $G$. vaginalis and $N$. gonorrhoeae $e^{25,31}$. Furthermore, some lactobacilli are thought to co-aggregate with pathogens; e.g., G. vaginalis, C. albicans and E. coli, thereby inhibiting them from binding to host cells and allowing more effective clearance ${ }^{32,33}$.

From the host perspective, several factors, including but not limited to the periodic hormonal cycling that promotes release of glycogen into the vaginal environment and the continual sloughing of the epithelial cells to which bacteria are attached, contribute to innate defenses against pathogen colonization. Presumably the collective activities of the host, in concert with inhibitory mechanisms of Lactobacillus, contribute to the maintenance of a healthy vaginal ecosystem.

\section{Healthy non-Lactobacillus dominated vaginal flora}

Although a prevalence of Lactobacillus species is the most common signature of a healthy microbiome, a significant proportion of apparently healthy women have vaginal bacterial communities that lack appreciable numbers of Lactobacillus species but include a diverse range of facultative or strictly anaerobic bacteria that are typically associated with slightly elevated $\mathrm{pH}$. These microbiota include members of the genera Atopobium, Corynebacterium, Anaerococcus, Peptoniphilus, Prevotella, Mobiluncus, Gardnerella and Sneathia, bacteria that are usually associated with a dysbiotic or diseased state $12,14,16,34-36$. Some of these bacteria, such as Atopobium can also produce lactic acid ${ }^{37}$. Thus the question remains whether certain bacterial taxa can play the role as either healthy commensal or pathogen, depending upon other factors.

\section{Factors that influence the microbiome}

Many factors influence the stability of the vaginal microbiota. The composition of vaginal communities fluctuate as a function of age, menarche, menses, pregnancy, infections, birth control and sexual behaviors ${ }^{17,38-41}$. Exposure to spermicides or $\beta$-lactam or other antimicrobials can decrease the prevalence of lactobacilli and consequently increase susceptibility to vaginal infections ${ }^{42,43}$.

Acquisition of the vaginal microbiome occurs shortly after or during birth. In utero, the fetus was once thought to exist in a sterile or near-sterile environment, but several cultureindependent studies now suggest the placental microbiome harbors low-abundance microbial communities ${ }^{44-46}$. With a vaginal delivery, the neonate is exposed to a diverse array of microbes, including those encountered during passage through the mother's birth canal. Culture-based studies in humans suggest that neonates acquire their initial microbiota from the vagina and feces of their mothers ${ }^{47}$. Dominguez-Bello et al. ${ }^{48}$ used targeted $16 \mathrm{~S}$ rRNA gene sequencing to show that vaginally delivered infants $(n=4)$ acquire microbial communities across skin, oral, nasopharyngeal and gut habitats similar to the vaginal microbiota of their mother, most commonly dominated by Lactobacillus, Prevotella, or Sneathia spp., whereas cesarean section delivered infants $(\mathrm{n}=6)$ acquire microbial communities similar to those inhabiting their mother's skin, dominated by Staphylococcus, Corynebacterium and Propionibacterium spp. Other studies have demonstrated that meconium of full term infants harbor bacteria ${ }^{49,50}$, indicating that gut colonization is seeded 
prior to birth. Additional studies have reported that the gastrointestninal tract of vaginally delivered newborns acquire several strains of Bifidobacterium from the intestine of the mother, suggesting that delivery mode and the mother's intestinal microbiota are key factors in establishing the infant's intestinal microbiota during early infancy ${ }^{51,52}$. It remains unclear how differences in the mode of delivery will impact development of the infant microbiome over time and what, if any, the subsequent effects on health will be.

Changes in the composition of the vaginal flora are driven by the dramatic hormonal shifts that occur throughout a woman's life. During early childhood, the vaginal $\mathrm{pH}$ is neutral or only slightly alkaline ${ }^{53-55}$. As estrogen levels rise during puberty, increased amounts of glycogen deposited in the vaginal epithelium permits the ascendance and eventual predominance of lactic-acid producing bacteria. As these bacteria ferment glycogen into glucose and eventually lactic acid ${ }^{56,57}$ the resulting lowered $\mathrm{pH}$ is thought to establish an inhospitable environment that is critical in preventing the propagation of many bacterial taxa, including many pathogenic or "less healthy" species. Traditionally, the high prevalence of lactic-acid producing bacteria has been considered the hallmark of vaginal health ${ }^{9}$, and, for many women, species of the genus Lactobacillus predominate the vaginal microbiome during the reproductive years ${ }^{58}$. As women approach menopause, estrogen levels decrease, glycogen content in the vaginal epithelium diminishes, and, as a result, lactobacilli decrease in prevalence ${ }^{59}$. With fewer lactobacilli present, less lactic acid is produced and the vaginal $\mathrm{pH}$ increases. Hormone replacement therapy (HRT) during and after menopause reverses this effect by increasing the glycogen content in the vaginal environment, which in turn has been reported to increase the predominance of Lactobacillus and significantly lower vaginal $\mathrm{pH}$ compared to postmenopausal women not undergoing $\mathrm{HRT}^{59-61}$.

The composition of vaginal bacterial communities differs dramatically among reproductive age women of different ethnic groups ${ }^{12-14}$. Ravel et al. ${ }^{12}$ analyzed the samples from 396 asymptomatic women and identified 5 community clusters: those predominated by $L$. iners, L. crispatus, L. gasseri, L. jensenii or had low proportions of lactobacilli and high proportions of strictly anaerobic bacteria. They found that $80-90 \%$ of the bacterial communities characterized in Asian $(n=97)$ and white $(n=98)$ women were dominated by species of Lactobacillus. In contrast, only $\sim 60 \%$ of Hispanic $(\mathrm{n}=97)$ and African American $(\mathrm{n}=104)$ women had vaginal microbiomes dominated by Lactobacilli. This compositional difference was reflected in the higher average $\mathrm{pH}$ values (i.e., $\mathrm{pH}>4.5$ ) recorded in Hispanic and African American women, which are above the range generally associated with vaginal health. A more extensive study by Fettweis et al. ${ }^{14}$ of vaginal samples from 1,686 African American women and 482 women of European ancestry showed similar results. However, in the latter study, two additional community clusters dominated by $G$. vaginalis or BVAB1 were observed, and a significant number of the samples, predominantly those from African American women, did not cluster into a common profile (Fig 1). Collectively, these findings reveal that the vaginal microbiome is much more heterogeneous and dynamic than commonly believed.

Although the influence of genetic factors on the vaginal microbiome is generally not well understood, a handful of genetic variants that impact vaginal health have been uncovered. The innate immune response in the female genital tract, which represents a pivotal defense 
against invading pathogens, represents one such genetically driven influence. Upon recognition of pathogen-associated molecular patterns (PAMPs) through interaction with toll-like receptors (TLRs), the innate immune response triggers secretion of a wide range of inflammatory mediators, chemokines and cytokines. Single nucleotide polymorphisms (SNPs) that disrupt proteins that mediate normal signaling or immune recognition have been associated with increased susceptibility to vaginal infections ${ }^{2,62,63}$. Moreover, polymorphisms in TLR4, TNF- $a$, IL-4 and IL-10 genes have been shown to induce aberrant responses to BV-associated bacteria related to preterm birth $^{62,64,65}$. Clearly, further investigation into the impact of environmental and genetic influences on the vaginal microbiome have a strong potential to improve diagnostics and contribute to the development of more personalized medicine relevant to urogenital health of women.

\section{The vaginal microbiome and disease}

The dynamic equilibrium of the vaginal microbiome can be altered by environmental factors and external interferences (e.g., antibiotics, vaginal hygiene, sexual intercourse, hormone therapy, etc.). These alterations can result in microbial imbalances or dysbiosis in the urogenital tract. As outlined above, the normally commensal bacterial communities present in the vagina can, under certain circumstances, become pathogenic (e.g., G. vaginalis, E. coli and $C$. albicans) if a shift in the equilibrium favors their competitiveness. Thus, changes in the vaginal microbiome can lead to intervals of increased susceptibility that negatively impact the ability of the community to resist pathogen colonization.

\section{Bacterial Vaginosis}

Bacterial vaginosis (BV) is a polymicrobial disorder and the most common vaginal imbalance in reproductive age women worldwide, affecting between $20-25 \%$ of the general population and upto $50 \%$ of women visiting sexual health clinics ${ }^{66,67}$. Although normally treatable with antibiotics, recurrence is the norm. Thus, BV represents a very significant public health challenge that predisposes affected women to sexually transmitted infections, pelvic inflammatory disease and numerous adverse pregnancy outcomes such as preterm birth and stillbirth ${ }^{68-70}$. While it remains uncertain whether BV can be sexually transmitted, studies have shown that BV increases the risk of transmission of HIV and other sexually transmitted diseases ${ }^{71,72}$. Although BV is not attributable to infection by a single pathogenic organism, multiple factors have been identified, including but not limited to, a new sexual partner, douching, smoking, and unsafe sexual practices that increase a woman's risk for BV. Relapsing BV is a major problem for many women, with recurrence rates greater than $50 \%$ within 12 months of treatment ${ }^{73}$.

Although its etiology is not well understood, and the disorder itself is rather loosely defined, $\mathrm{BV}$ is generally considered to be characterized by the disruption of the normal vaginal ecosystem marked by depletion of lactobacilli, and overgrowth of various gram negative and/ or anerobic bacteria, including G. vaginalis, A. vaginae, Megasphaera phylotype 1 species, Mobiluncus spp., Ureaplasma urealyticum, Provetella, Peptostreptococcus and Mycoplasma hominis ${ }^{74,75}$. Although BV is considered a polymicrobial disease, G. vaginalis has been promoted as an important contributor in the pathogenesis of $\mathrm{BV}$ and is present in 
$95 \%$ of cases ${ }^{76}$. G. vaginalis adheres to and establishes a biofilm on the vaginal epithelium and secretes a cytotoxin that has the potential to disrupt and kill epithelial cells ${ }^{76}$. The massive increase of vaginal anaerobes in BV is associated with heightened production of proteolytic enzymes and the subsequent breakdown of vaginal peptides to a variety of amines. In high $\mathrm{pH}$ environments the amines become malodorous, contribute to the typical vaginal discharge and trigger the release of pro-inflammatory cytokines such as IL- $1 \beta$ and IL- $8^{77,78}$. Women with BV typically complain of vaginal discharge and a fishy malodor. However, a substantial fraction of women with bacterial populations characteristic of BV are asymptomatic and report no clinical complaints.

$\mathrm{BV}$ is typically diagnosed based on the presence of three of the following Amsel criteria ${ }^{79}$ : i) an elevated vaginal $\mathrm{pH}(>4.5)$; ii) a thin, homogeneous gray-white discharge; iii) a fishy odor upon the addition of $10 \%$ potassium hydroxide to vaginal fluid on a glass slide; and $i v$ ) presence of clue cells (squamous epithelial cells covered with adherent bacteria) on microscopic examination of vaginal fluid. Alternatively, in research and laboratory settings, $\mathrm{BV}$ is diagnosed by scoring a Gram-stained vaginal smear using the Nugent criteria ${ }^{80}$. The Nugent score assumes high numbers of Lactobacillus species are indicative of health, and their depletion coupled with increased numbers of small and/or curved Gram-variable rods is indicative of $\mathrm{BV}$.

It is well established that there is a greater incidence of BV among African American women. Fettweis et al. ${ }^{14}$ compared the microbiome profiles of African American women and women of European ancestry with and without a clinical diagnosis of BV (Fig. 1). Of the healthy subjects, those who did not receive a clinical diagnosis, African American women $(n=728)$ were more likely to be colonized by strict anaerobes, whereas women of European ancestry were more likely colonized by $L$. crispatus, $L$. gasseri and $L$. jensenii. Furthermore, of the participants with a positive diagnosis for BV, African American women ( $\mathrm{n}=373$ ) were more likely colonized by Anaerococcus tetradius, BVAB1 and BVAB3, Coriobacteriaceae, Sneathia species, Parvimonas, Dialister, Megasphaera, Bulledia, Prevotella species and A. vaginae, whereas women of European ancestry were more likely colonized by M. hominis, Dialister micraerophilus and an undefined Gemella species. This study extends previous findings ${ }^{16,57}$ that, even among apparently health women, African American ethnicity is associated with a vaginal microbiome that more closely resembles $\mathrm{BV}$, characterized by an increase in species diversity and decrease in lactobacilli (Fig. 1). As of yet, the basis for this disparity remains unclear. The increased risk of BV among African American women parallels their increased risk for preterm birth, and a cause and effect relationship is sometimes inferred. However, the role of this microbial diversity in adverse outcomes in pregnancy remains unproven, and a better understanding of the factors associated with ethnicity that contribute to the vaginal microbiome has important implications for reproductive health.

Several vaginal species; e g., L. iners, P. bivia and A. vaginae, have been detected in vaginal samples from healthy women and from women with BV, indicating that these species have evolved mechanisms to persist in vastly differing environments. Among the vaginal lactobacilli $L$. iners is unique in it's ablility to survive in a BV-like environment. In a recent study, Macklaim et al. ${ }^{81}$ used RNA-seq strategies to describe the difference in gene 
expression profiles of $L$. iners isolated from healthy women and women with BV environments ${ }^{81,82}$. These studies showed that $L$. iners upregulates expression of a cholesterol-dependent cytolysin (CDC) in a woman with BV. CDCs belong to a family of pore-forming toxins that are common to many pathogenic bacteria, including G. vaginalis, but absent in L. crispatus, L. jensenii or L. gasseri. The L. iners encoded CDC exhibits 55\% amino acid identity to the vaginolysin of $G$. vaginalis, which is thought to induce epithelial cell cytotoxicity ${ }^{83,84}$. In contrast to the lactic acid-rich environment of the classical healthy vagina, the dominant metabolic byproducts of $L$. iners in the vagina of a woman with BV include succinate and a panel of short-chain fatty acids. Relevant to BV, increased production of succinate supports the growth of anaerobic bacteria. This study ${ }^{81}$ demonstrates the ability of $L$. iners to regulate gene expression depending on environmental factors (i.e., bacterial composition, $\mathrm{pH}$ ) and highlights the need for metatranscriptomic analyses to fully resolve species-specific interactions in the context of the host and community.

While A. vaginae has been associated with both healthy, asymptomatic women and women with $\mathrm{BV}$, there has been debate over whether this lactic acid-producing species is a common component of the vaginal microbiota. A recent study using in vitro colonization of vaginal epithelial cell monolayers with $L$. crispatus, L. iners, P. bivia and A. vaginae demonstrated that each species triggers a unique innate immune signature ${ }^{2}$. Consistent with the apparently beneficial role of $L$. crispatus, exposure of this bacterium to epithelial cells resulted in lowlevel immune activation. Alternatively, A. vaginae elicited a robust inflammatory response and increased expression of mucin-encoding genes ${ }^{2}$. Furthermore, studies have reported an association between increased levels of $A$. vaginae and G. vaginalis with preterm labor ${ }^{85}$.

\section{Pregnancy and Preterm Birth}

The vaginal microbiome changes during pregnancy, growing increasingly homogeneous as pregnancy progresses ${ }^{86,87}$. A recent longitudinal study by Romero et al. ${ }^{87}$ analyzed the taxonomic 16S rRNA profiles of vaginal samples from 22 pregnant and 32 non-pregnant women to investigate the temporal dynamics of the vaginal microbiota stability throughout pregnancy. They reported that the microbial communities of non-pregnant women sometimes undergo regular shifts in the representation and abundance of Lactobacillus species. In contrast, throughout pregnancy the vaginal microbiota is normally dominated by Lactobacillus species.

Preterm birth (PTB), defined as a birth prior to 37 weeks gestation, affects more than $11.5 \%$ of births and contributes to more than one third of all infant deaths ${ }^{88,89}$. Very PTBs $(<32$ weeks) are commonly the result of infection in the uterine cavity caused by ascension of vaginal bacteria through the cervix ${ }^{90}$. The most prevalent species associated with PTB are U. urealyticum, M. hominis, Bacteroides spp., G. vaginalis and Fusobacterium nucleatum $^{90,91}$. Bacteria identified in PTB-associated infections have been detected in umbilical cord blood, amniotic fluid, fetal membranes and placenta ${ }^{90}$. However, infection of the uterine cavity does not always lead to adverse outcome and studies suggest that inflammation plays a more direct role in $\mathrm{PTB}^{92}$. 
It is well established that diagnosed BV is associated with an increased risk for PTB, but the most prominent risk factor for $\mathrm{PTB}$ is a previous $\mathrm{PTB}^{93}$. As outlined above, this observation is also consistent with the fact that $\mathrm{BV}$ is a recurrent if not chronic problem for many women. A recent study reported that, among women with a history of PTB, women with high levels of Sneathia species, BVAB1 and Mobiluncus species early in pregnancy, were significantly more likely to experience a spontaneous $\mathrm{PTB}^{94}$. We recently reported that the genome of a Sneathia amnii strain from a woman who experienced preterm birth bears various potential pathogenic determinants including cytotoxins and adhesins. We also demonstrated S. amnii forms pores in and kills eukaryotic cells in culture ${ }^{36}$. Continued identification and study of bacteria with strong predictive value holds promise for developing more effective prophylactic and therapeutic approaches to reduce rates of preterm birth.

\section{Concluding Remarks}

Although not as diverse as the gut or oral microbiomes, deep sequence analysis of the vaginal microbiome is revealing an unexpected complexity that was not anticipated as recently as several years ago. Studies have revealed that women can be clustered into a finite number of groups based on the profile and complexity of the microbiomes. Some of these groups are diverse and comprised of complex combinations of bacterial taxa. Defying convention, even apparently healthy women often display these complex microbiome profiles. Conversely, many women with BV exhibit homogenous vaginal microbiomes dominated by lactobacilli, underscoring the likely multiple etiologies of the syndrome of $\mathrm{BV}$, and calling for more diagnostic accuracy and resolution. African women have more diverse microbiomes, more BV and more PTB than women of European ancestry. However, the lack of clarity in the definition of a healthy vaginal microbiome, much less an unhealthy vaginal microbiome, underscores the need for more investigation of these phenomena. Some clarity may be gained by the careful analysis of the genomes of the specific bacteria in these women. We know that bacteria with identical 16S rRNA sequences (e.g., the many strains of E. coli) have vastly different pathogenic potentials. Thus, it may not be surprising that one healthy woman's vaginal microbiome is dominanted by G. vaginalis with an identical $16 \mathrm{~S}$ rRNA signature to that of a G. vaginalis strain populating the vagina of a woman with BV or other unhealthy condition. Ongoing studies will clarify this process, and offer relief for women with recurring vaginal maladies and hope for pregnant women to avoid the experience of PTB.

\section{Acknowledgments}

We thank members of the Vaginal Microbiome Consortium (vmc.vcu.edu) at VCU for their effort and inspiration in generation of the data and its analysis associated with this publication. This work was supported by National Institutes of Health grants 4UH3AI083263, The Vaginal Microbiome: Disease, Genetics and the Environment, and 8U54HD080784 Multi-omic Analysis of the Vaginal Microbiome During Pregnancy (MOMS-PI). Sequence analysis was performed in the Nucleic Acids Research Facilities at VCU. Bioinformatics analysis was provided by the staff of the Bioinformatics Computational Core Laboratories at VCU.

This work was supported NIH grants 8U54HD080784 and 1UH3AI083263 to G.A.B. 


\section{References}

1. Cash HL, Whitham CV, Behrendt CL, Hooper LV. Symbiotic bacteria direct expression of an intestinal bactericidal lectin. Science. 2006; 313(5790):1126-30.10.1126/science.1127119 [PubMed: 16931762]

2. Doerflinger SY, Throop AL, Herbst-Kralovetz MM. Bacteria in the vaginal microbiome alter the innate immune response and barrier properties of the human vaginal epithelia in a species-specific manner. J Infect Dis. 201410.1093/infdis/jiu004

3. Peterson J, Garges S, et al. NIH HMP Working Group. The nIH human microbiome project. Genome Res. 2009; 19(12):2317-23.10.1101/gr.096651.109 [PubMed: 19819907]

4. Ehrlich, S. MetaHIT: The european union project on metagenomics of the human intestinal tract. In: Nelson, KE., editor. Metagenomics of the Human Body. Springer; New York: 2011. p. 307-316.

5. Arumugam M, Raes J, Pelletier E, et al. Enterotypes of the human gut microbiome. Nature. 2011; 473(7346):174-80.10.1038/nature09944 [PubMed: 21508958]

6. Anderson LS, Beverly WT, Corey LA, Murrelle L. The mid-atlantic twin registry. Twin Res. 2002; 5(5):449-55.10.1375/136905202320906264 [PubMed: 12537875]

7. Kuczynski J, Lauber CL, Walters WA, et al. Experimental and analytical tools for studying the human microbiome. Nat Rev Genet. 2012; 13(1):47-58.10.1038/nrg3129 [PubMed: 22179717]

8. Fettweis JM, Serrano MG, Sheth NU, et al. Species-level classification of the vaginal microbiome. BMC Genomics. 2012; 13(Suppl 8):S17.10.1186/1471-2164-13-S8-S17 [PubMed: 23282177]

9. Donders GG, Bosmans E, Dekeersmaecker A, Vereecken A, Van Bulck B, Spitz B. Pathogenesis of abnormal vaginal bacterial flora. Am J Obstet Gynecol. 2000; 182(4):872-8. [PubMed: 10764465]

10. Aroutcheva A, Gariti D, Simon M, et al. Defense factors of vaginal lactobacilli. Am J Obstet Gynecol. 2001; 185(2):375-9.10.1067/mob.2001.115867 [PubMed: 11518895]

11. Eschenbach DA, Davick PR, Williams BL, et al. Prevalence of hydrogen peroxide-producing lactobacillus species in normal women and women with bacterial vaginosis. J Clin Microbiol. 1989; 27(2):251-6. [PubMed: 2915019]

12. Ravel J, Gajer P, Abdo Z, et al. Vaginal microbiome of reproductive-age women. Proceedings of the National Academy of Sciences of the United States of America. 2011; 108(Suppl 1):46804687. [PubMed: 20534435]

13. Yamamoto T, Zhou X, Williams CJ, Hochwalt A, Forney LJ. Bacterial populations in the vaginas of healthy adolescent women. Journal of pediatric and adolescent gynecology. 2009; 22(1):11-18. [PubMed: 19232297]

14. Fettweis JM, Brooks JP, Serrano MG, et al. Differences in vaginal microbiome in african american women versus women of european ancestry. Microbiology. 201410.1099/mic.0.081034-0

15. Pavlova SI, Kilic AO, Kilic SS, et al. Genetic diversity of vaginal lactobacilli from women in different countries based on 16S rRNA gene sequences. J Appl Microbiol. 2002; 92(3):451-9. [PubMed: 11872120]

16. Zhou X, Bent SJ, Schneider MG, Davis CC, Islam MR, Forney LJ. Characterization of vaginal microbial communities in adult healthy women using cultivation-independent methods. Microbiology (Reading, England). 2004; 150(Pt 8):2565-2573.

17. Gajer P, Brotman RM, Bai G, et al. Temporal dynamics of the human vaginal microbiota. Sci Transl Med. 2012; 4(132):132ra52.10.1126/scitranslmed.3003605

18. Witkin SS, Mendes-Soares H, Linhares IM, Jayaram A, Ledger WJ, Forney LJ. Influence of vaginal bacteria and d- and 1-lactic acid isomers on vaginal extracellular matrix metalloproteinase inducer: implications for protection against upper genital tract infections. MBio. 2013; 4(4)10.1128/mBio.00460-13

19. O'Hanlon DE, Moench TR, Cone RA. Vaginal $\mathrm{pH}$ and microbicidal lactic acid when lactobacilli dominate the microbiota. PLoS One. 2013; 8(11):e80074.10.1371/journal.pone.0080074 [PubMed: 24223212]

20. O'Hanlon DE, Moench TR, Cone RA. In vaginal fluid, bacteria associated with bacterial vaginosis can be suppressed with lactic acid but not hydrogen peroxide. BMC Infect Dis. 2011; 11:200.10.1186/1471-2334-11-200 [PubMed: 21771337] 
21. O'Hanlon DE, Lanier BR, Moench TR, Cone RA. Cervicovaginal fluid and semen block the microbicidal activity of hydrogen peroxide produced by vaginal lactobacilli. BMC Infect Dis. 2010; 10:120.10.1186/1471-2334-10-120 [PubMed: 20482854]

22. Selle K, Klaenhammer TR. Genomic and phenotypic evidence for probiotic influences of lactobacillus gasseri on human health. FEMS Microbiol Rev. 2013; 37(6):91535.10.1111/1574-6976.12021 [PubMed: 23488471]

23. Zárate G, Nader-Macias ME. Influence of probiotic vaginal lactobacilli on in vitro adhesion of urogenital pathogens to vaginal epithelial cells. Lett Appl Microbiol. 2006; 43(2):17480.10.1111/j.1472-765X.2006.01934.x [PubMed: 16869901]

24. Zárate G, Santos V, Nader-Macias ME. Protective effect of vaginal lactobacillus paracasei cRL 1289 against urogenital infection produced by staphylococcus aureus in a mouse animal model. Infect Dis Obstet Gynecol. 2009; 2009:48358.10.1155/2007/48358 [PubMed: 17485818]

25. Boris S, Suárez JE, Vázquez F, Barbés C. Adherence of human vaginal lactobacilli to vaginal epithelial cells and interaction with uropathogens. Infect Immun. 1998; 66(5):1985-9. [PubMed: 9573080]

26. O'Sullivan O, O'Callaghan J, Sangrador-Vegas A, et al. Comparative genomics of lactic acid bacteria reveals a niche-specific gene set. BMC Microbiol. 2009; 9:50.10.1186/1471-2180-9-50 [PubMed: 19265535]

27. Mendes-Soares H, Suzuki H, Hickey RJ, Forney LJ. Comparative functional genomics of lactobacillus spp. reveals possible mechanisms for specialization of vaginal lactobacilli to their environment. J Bacteriol. 201410.1128/JB.01439-13

28. Atassi F, Brassart D, Grob P, Graf F, Servin AL. Lactobacillus strains isolated from the vaginal microbiota of healthy women inhibit prevotella bivia and gardnerella vaginalis in coculture and cell culture. FEMS Immunol Med Microbiol. 2006; 48(3):424-32.10.1111/j.1574-695X. 2006.00162.x [PubMed: 17059467]

29. Kaewsrichan J, Peeyananjarassri K, Kongprasertkit J. Selection and identification of anaerobic lactobacilli producing inhibitory compounds against vaginal pathogens. FEMS Immunol Med Microbiol. 2006; 48(1):75-83.10.1111/j.1574-695X.2006.00124.x [PubMed: 16965354]

30. Osset J, Bartolomé RM, García E, Andreu A. Assessment of the capacity of lactobacillus to inhibit the growth of uropathogens and block their adhesion to vaginal epithelial cells. J Infect Dis. 2001; 183(3):485-91.10.1086/318070 [PubMed: 11133381]

31. Spurbeck RR, Arvidson CG. Inhibition of neisseria gonorrhoeae epithelial cell interactions by vaginal lactobacillus species. Infect Immun. 2008; 76(7):3124-30.10.1128/IAI.00101-08 [PubMed: 18411284]

32. Mastromarino P, Brigidi P, Macchia S, et al. Characterization and selection of vaginal lactobacillus strains for the preparation of vaginal tablets. J Appl Microbiol. 2002; 93(5):884-93. [PubMed: 12392537]

33. Reid G, McGroarty JA, Angotti R, Cook RL. Lactobacillus inhibitor production against escherichia coli and coaggregation ability with uropathogens. Can J Microbiol. 1988; 34(3):344-51. [PubMed: 3138017]

34. Hyman RW, Fukushima M, Diamond L, Kumm J, Giudice LC, Davis RW. Microbes on the human vaginal epithelium. Proc Natl Acad Sci U S A. 2005; 102(22):7952-7.10.1073/pnas.0503236102 [PubMed: 15911771]

35. Verhelst R, Verstraelen H, Claeys G, et al. Cloning of 16S rRNA genes amplified from normal and disturbed vaginal microflora suggests a strong association between Atopobium vaginae, Gardnerella vaginalis and bacterial vaginosis. BMC microbiology. 2004; 4:16. [PubMed: 15102329]

36. Harwich MD Jr, Serrano MG, Fettweis JM, et al. Genomic sequence analysis and characterization of sneathia amnii sp. nov. BMC Genomics. 2012; 13(Suppl 8):S4.10.1186/1471-2164-13-S8-S4 [PubMed: 23281612]

37. Shi Y, Chen L, Tong J, Xu C. Preliminary characterization of vaginal microbiota in healthy chinese women using cultivation-independent methods. J Obstet Gynaecol Res. 2009; 35(3):52532.10.1111/j.1447-0756.2008.00971.x [PubMed: 19527394] 
38. Witkin SS, Ledger WJ. Complexities of the uniquely human vagina. Sci Transl Med. 2012; 4(132): 132fs 11.10.1126/scitranslmed.3003944

39. Johnson SR, Petzold CR, Galask RP. Qualitative and quantitative changes of the vaginal microbial flora during the menstrual cycle. Am J Reprod Immunol Microbiol. 1985; 9(1):1-5. [PubMed: 4051082]

40. Eschenbach DA, Thwin SS, Patton DL, et al. Influence of the normal menstrual cycle on vaginal tissue, discharge, and microflora. Clinical infectious diseases : an official publication of the Infectious Diseases Society of America. 2000; 30(6):901-907. [PubMed: 10852812]

41. Mitchell CM, Fredricks DN, Winer RL, Koutsky L. Effect of sexual debut on vaginal microbiota in a cohort of young women. Obstet Gynecol. 2012; 120(6):1306-13. doi:http://10.1097/AOG. 0b013e31827075ac. [PubMed: 23168754]

42. Hooton TM, Fennell CL, Clark AM, Stamm WE. Nonoxynol-9: differential antibacterial activity and enhancement of bacterial adherence to vaginal epithelial cells. J Infect Dis. 1991; 164(6): 1216-9. [PubMed: 1659602]

43. Hooton TM, Hillier S, Johnson C, Roberts PL, Stamm WE. Escherichia coli bacteriuria and contraceptive method. JAMA. 1991; 265(1):64-9. [PubMed: 1859519]

44. Aagaard K, Ma J, Antony KM, Ganu R, Petrosino J, Versalovic J. The placenta harbors a unique microbiome. Sci Transl Med. 2014; 6(237):237ra65.10.1126/scitranslmed.3008599

45. Stout MJ, Conlon B, Landeau M, et al. Identification of intracellular bacteria in the basal plate of the human placenta in term and preterm gestations. Am J Obstet Gynecol. 2013; 208(3):226.e17.10.1016/j.ajog.2013.01.018 [PubMed: 23333552]

46. Romero R, Schaudinn C, Kusanovic JP, et al. Detection of a microbial biofilm in intraamniotic infection. Am J Obstet Gynecol. 2008; 198(1):135.e1-5.10.1016/j.ajog.2007.11.026 [PubMed: 18166328]

47. Mändar R, Mikelsaar M. Transmission of mother's microflora to the newborn at birth. Biol Neonate. 1996; 69(1):30-5. [PubMed: 8777246]

48. Dominguez-Bello MG, Costello EK, Contreras M, et al. Delivery mode shapes the acquisition and structure of the initial microbiota across multiple body habitats in newborns. Proceedings of the National Academy of Sciences of the United States of America. 2010; 107(26):11971-11975. [PubMed: 20566857]

49. Jiménez E, Marín ML, Martín R, et al. Is meconium from healthy newborns actually sterile? Res Microbiol. 2008; 159(3):187-93.10.1016/j.resmic.2007.12.007 [PubMed: 18281199]

50. Ardissone AN, Cruz DM de la, Davis-Richardson AG, et al. Meconium microbiome analysis identifies bacteria correlated with premature birth. PLoS One. 2014; 9(3):e90784.10.1371/ journal.pone.0090784 [PubMed: 24614698]

51. Makino H, Kushiro A, Ishikawa E, et al. Transmission of intestinal bifidobacterium longum subsp. longum strains from mother to infant, determined by multilocus sequencing typing and amplified fragment length polymorphism. Appl Environ Microbiol. 2011; 77(19):6788-93.10.1128/AEM. 05346-11 [PubMed: 21821739]

52. Makino H, Kushiro A, Ishikawa E, et al. Mother-to-infant transmission of intestinal bifidobacterial strains has an impact on the early development of vaginally delivered infant's microbiota. PLoS One. 2013; 8(11):e78331.10.1371/journal.pone.0078331 [PubMed: 24244304]

53. Hammerschlag MR, Alpert S, Rosner I, et al. Microbiology of the vagina in children: normal and potentially pathogenic organisms. Pediatrics. 1978; 62(1):57-62. [PubMed: 98750]

54. Hammerschlag MR, Alpert S, Onderdonk AB, et al. Anaerobic microflora of the vagina in children. Am J Obstet Gynecol. 1978; 131(8):853-6. [PubMed: 686083]

55. Jaquiery A, Stylianopoulos A, Hogg G, Grover S. Vulvovaginitis: clinical features, aetiology, and microbiology of the genital tract. Arch Dis Child. 1999; 81(1):64-7. [PubMed: 10373139]

56. Paavonen J. Physiology and ecology of the vagina. Scandinavian journal of infectious diseases Supplementum. 1983; 40:31-35. [PubMed: 6582587]

57. Zhou X, Brown CJ, Abdo Z, et al. Differences in the composition of vaginal microbial communities found in healthy Caucasian and black women. The ISME journal. 2007; 1(2):121133. [PubMed: 18043622] 
58. Jennifer, Fettweis A.; Buck, G. The vaginal microbiome: Disease, genetics and the environment. 2011. Available from Nature Precedings <http://dxdoiorg/101038/npre201151502

59. Gupta S, Kumar N, Singhal N, Kaur R, Manektala U. Vaginal microflora in postmenopausal women on hormone replacement therapy. Indian J Pathol Microbiol. 2006; 49(3):457-61. [PubMed: 17001923]

60. Burton JP, Reid G. Evaluation of the bacterial vaginal flora of 20 postmenopausal women by direct (Nugent score) and molecular (polymerase chain reaction and denaturing gradient gel electrophoresis) techniques. The Journal of infectious diseases. 2002; 186(12):1770-1780. [PubMed: 12447763]

61. Pabich WL, Fihn SD, Stamm WE, Scholes D, Boyko EJ, Gupta K. Prevalence and determinants of vaginal flora alterations in postmenopausal women. J Infect Dis. 2003; 188(7):10548.10.1086/378203 [PubMed: 14513427]

62. Genc MR, Onderdonk A. Endogenous bacterial flora in pregnant women and the influence of maternal genetic variation. BJOG. 2011; 118(2):154-63.10.1111/j.1471-0528.2010.02772.x [PubMed: 21054765]

63. Verstraelen H, Verhelst R, Nuytinck L, et al. Gene polymorphisms of toll-like and related recognition receptors in relation to the vaginal carriage of gardnerella vaginalis and atopobium vaginae. J Reprod Immunol. 2009; 79(2):163-73.10.1016/j.jri.2008.10.006 [PubMed: 19200604]

64. Genc MR, Schantz-Dunn J. The role of gene-environment interaction in predicting adverse pregnancy outcome. Best Pract Res Clin Obstet Gynaecol. 2007; 21(3):491-504.10.1016/ j.bpobgyn.2007.01.009 [PubMed: 17369098]

65. Jones NM, Holzman C, Friderici KH, et al. Interplay of cytokine polymorphisms and bacterial vaginosis in the etiology of preterm delivery. J Reprod Immunol. 2010; 87(1-2):82-9.10.1016/j.jri. 2010.06.158 [PubMed: 20965572]

66. Morris M, Nicoll A, Simms I, Wilson J, Catchpole M. Bacterial vaginosis: a public health review. BJOG : an international journal of obstetrics and gynaecology. 2001; 108(5):439-450. [PubMed: 11368127]

67. Srinivasan S, Fredricks DN. The human vaginal bacterial biota and bacterial vaginosis. Interdiscip Perspect Infect Dis. 2008; 2008:750479.10.1155/2008/750479 [PubMed: 19282975]

68. Leitich H, Bodner-Adler B, Brunbauer M, Kaider A, Egarter C, Husslein P. Bacterial vaginosis as a risk factor for preterm delivery: a meta-analysis. American journal of obstetrics and gynecology. 2003; 189(1):139-147. [PubMed: 12861153]

69. Hillier SL, Krohn MA, Cassen E, Easterling TR, Rabe LK, Eschenbach DA. The role of bacterial vaginosis and vaginal bacteria in amniotic fluid infection in women in preterm labor with intact fetal membranes. Clin Infect Dis. 1995; 20(Suppl 2):S276-8. [PubMed: 7548574]

70. Sweet RL. Role of bacterial vaginosis in pelvic inflammatory disease. Clin Infect Dis. 1995; 20(Suppl 2):S271-5. [PubMed: 7548573]

71. Schmid G, Markowitz L, Joesoef R, Koumans E. Bacterial vaginosis and HIV infection. Sexually Transmitted Infections. 2000; 76(1):3-4. [PubMed: 10817059]

72. Wiesenfeld HC, Hillier SL, Krohn MA, Landers DV, Sweet RL. Bacterial vaginosis is a strong predictor of neisseria gonorrhoeae and chlamydia trachomatis infection. Clin Infect Dis. 2003; 36(5):663-8.10.1086/367658 [PubMed: 12594649]

73. Bradshaw CS, Morton AN, Hocking J, et al. High recurrence rates of bacterial vaginosis over the course of 12 months after oral metronidazole therapy and factors associated with recurrence. J Infect Dis. 2006; 193(11):1478-86.10.1086/503780 [PubMed: 16652274]

74. Fredricks DN, Fiedler TL, Marrazzo JM. Molecular identification of bacteria associated with bacterial vaginosis. The New England journal of medicine. 2005; 353(18):1899-1911. [PubMed: 16267321]

75. Swidsinski A, Mendling W, Loening-Baucke V, et al. Adherent biofilms in bacterial vaginosis. Obstet Gynecol. 2005; 106(5 Pt 1):1013-23.10.1097/01.AOG.0000183594.45524.d2 [PubMed: 16260520]

76. Patterson JL, Stull-Lane A, Girerd PH, Jefferson KK. Analysis of adherence, biofilm formation and cytotoxicity suggests a greater virulence potential of gardnerella vaginalis relative to other 
bacterial-vaginosis-associated anaerobes. Microbiology. 2010; 156(Pt 2):392-9.10.1099/mic. 0.034280-0 [PubMed: 19910411]

77. Hedges SR, Barrientes F, Desmond RA, Schwebke JR. Local and systemic cytokine levels in relation to changes in vaginal flora. J Infect Dis. 2006; 193(4):556-62.10.1086/499824 [PubMed: 16425135]

78. Beigi RH, Yudin MH, Cosentino L, Meyn LA, Hillier SL. Cytokines, pregnancy, and bacterial vaginosis: comparison of levels of cervical cytokines in pregnant and nonpregnant women with bacterial vaginosis. J Infect Dis. 2007; 196(9):1355-60.10.1086/521628 [PubMed: 17922400]

79. Amsel R, Totten PA, Spiegel CA, Chen KC, Eschenbach D, Holmes KK. Nonspecific vaginitis. diagnostic criteria and microbial and epidemiologic associations. Am J Med. 1983; 74(1):14-22. [PubMed: 6600371]

80. Nugent RP, Krohn MA, Hillier SL. Reliability of diagnosing bacterial vaginosis is improved by a standardized method of gram stain interpretation. J Clin Microbiol. 1991; 29(2):297-301. [PubMed: 1706728]

81. Macklaim JM, fernandes AD, Di Bella JM, Hammond JA, Reid G, Gloor GB. Comparative metaRNA-seq of the vaginal microbiota and differential expression by Lactobacillus iners in health and dysbiosis. Microbiome. 2013:1-11. [PubMed: 24467924]

82. Zozaya-Hinchliffe M, Lillis R, Martin DH, Ferris MJ. Quantitative pCR assessments of bacterial species in women with and without bacterial vaginosis. J Clin Microbiol. 2010; 48(5):1812_ 9.10.1128/JCM.00851-09 [PubMed: 20305015]

83. Randis TM, Zaklama J, LaRocca TJ, et al. Vaginolysin drives epithelial ultrastructural responses to gardnerella vaginalis. Infect Immun. 2013; 81(12):4544-50.10.1128/IAI.00627-13 [PubMed: 24082080]

84. Macklaim JM, Gloor GB, Anukam KC, Cribby S, Reid G. At the crossroads of vaginal health and disease, the genome sequence of lactobacillus iners aB-1. Proc Natl Acad Sci U S A. 2011; 108(Suppl 1):4688-95.10.1073/pnas.1000086107 [PubMed: 21059957]

85. Menard JP, Fenollar F, Henry M, Bretelle F, Raoult D. Molecular quantification of gardnerella vaginalis and atopobium vaginae loads to predict bacterial vaginosis. Clin Infect Dis. 2008; 47(1): 33-43.10.1086/588661 [PubMed: 18513147]

86. Aagaard K, Riehle K, Ma J, et al. A metagenomic approach to characterization of the vaginal microbiome signature in pregnancy. PLoS One. 2012; 7(6):e36466.10.1371/journal.pone.0036466 [PubMed: 22719832]

87. Romero R, Hassan SS, Gajer P, et al. The composition and stability of the vaginal microbiota of normal pregnant women is different from that of non-pregnant women. Microbiome. 2014; 2(1): 4.10.1186/2049-2618-2-4 [PubMed: 24484853]

88. Goldenberg RL, Culhane JF, Iams JD, Romero R. Epidemiology and causes of preterm birth. Lancet. 2008; 371(9606):75-84.10.1016/S0140-6736(08)60074-4 [PubMed: 18177778]

89. Iacovidou N, Varsami M, Syggellou A. Neonatal outcome of preterm delivery. Annals of the New York Academy of Sciences. 2010; 1205:130-134. [PubMed: 20840264]

90. Goldenberg RL, Hauth JC, Andrews WW. Intrauterine infection and preterm delivery. N Engl J Med. 2000; 342(20):1500-7.10.1056/NEJM200005183422007 [PubMed: 10816189]

91. Jefferson KK. The bacterial etiology of preterm birth. Adv Appl Microbiol. 2012; 80:122.10.1016/B978-0-12-394381-1.00001-5 [PubMed: 22794142]

92. Combs CA, Gravett M, Garite TJ, et al. Amniotic fluid infection, inflammation, and colonization in preterm labor with intact membranes. Am J Obstet Gynecol. 2014; 210(2):125.e1125.e15.10.1016/j.ajog.2013.11.032 [PubMed: 24274987]

93. Mercer BM, Goldenberg RL, Moawad AH, et al. The preterm prediction study: effect of gestational age and cause of preterm birth on subsequent obstetric outcome. national institute of child health and human development maternal-fetal medicine units network. Am J Obstet Gynecol. 1999; 181(5 Pt 1):1216-21. [PubMed: 10561648]

94. Nelson DB, Hanlon A, Nachamkin I, et al. Early pregnancy changes in bacterial vaginosisassociated bacteria and preterm delivery. Paediatr Perinat Epidemiol. 201410.1111/ppe.12106 


\section{Key points}

- The vaginal microenvironment is a dynamic ecosystem in which the microbiota play a major role in regulating parameters such as $\mathrm{pH}$ and in limiting the growth of potentially harmful organisms.

- Alterations in the vaginal microbiota can impact the community's ability to inhibit pathogenesis of disease-causing organisms in the femal urogenital tract.

- Bacterial vaginosis is broadly, but apparently only poorly, defined by the disruption of the normal vaginal ecosystem marked by depletion of lactobacilli and overgrowth of anaerobic bacteria. 

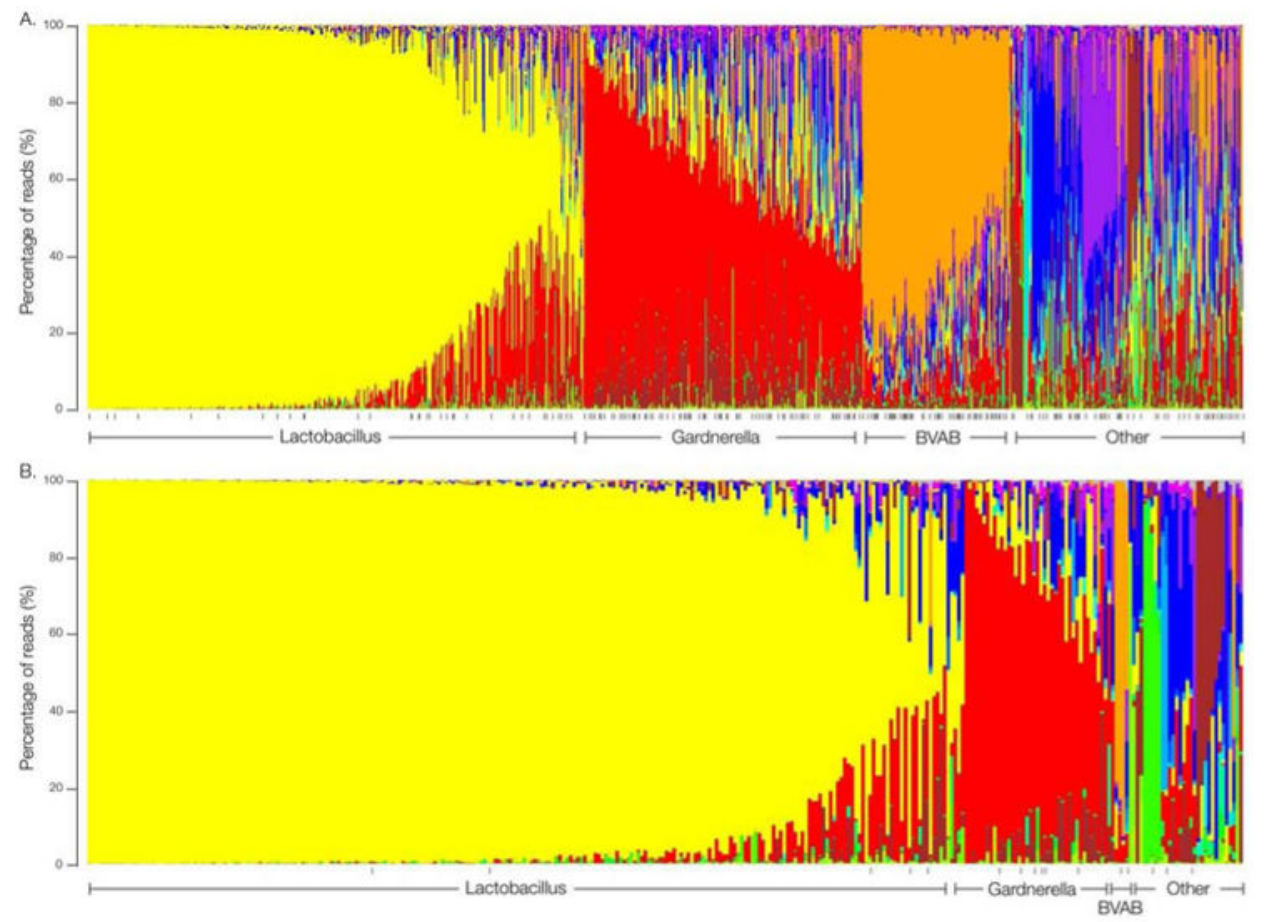

Figure 1.

Microbiome profiles of women of African American or European ancestry.

Mid-vaginal relative abundance profiles using genus-level classification from (A) 960

African American women and (B) 330 women of European ancestry enrolled in the Vaginal Human Microbiome Project at VCU. The profiles are clustered by the dominant genus into different community types. All processed samples were represented by $>5,000$ reads. See Fettweis et al. ${ }^{14}$ for methodology. Black vertical dashes represent women with a clinical BV diagnosis.

Data From: Fettweis JM, Brooks JP, Serrano MG, et al. Differences in vaginal microbiome in African American women versus women of European ancestry. Microbiology. 2014 [Epub ahead of print] 